\title{
Acute Immunologic Arthritis in Rabbits
}

\author{
Claude V. DeShazo, Peter M. Henson, and Charles G. Cochrane \\ From the Department of Experimental Pathology, Scripps Clinic and \\ Research Foundation, La Jolla, California 92037
}

\begin{abstract}
A B S T RACT Mediators of acute immunologic injury have been studied in vivo by producing arthritis in rabbit knee joints. A reversed passive Arthus lesion was produced by injecting antibody into the joint space and antigen intravenously. Injury was assessed by measuring leakage of serum proteins and circulating radiolabeled proteins into the joint space and by the accumulation of neutrophils in the joint fluid. Inflammatory exudate was recovered for study by a standardized irrigation technique.
\end{abstract}

Maximal vascular permeability developed $2 \mathrm{hr}$ after injection as neutrophils accumulated about immune complexes in venule walls to produce structural injury. After $5 \mathrm{hr}$ the number of neutrophils in the joint space rose rapidly, followed by a second rise in permeability at $8 \mathrm{hr}$. Neutrophil depletion abolished both peaks of permeability. It was then possible to reconstitute the synovial lesion in neutrophil-depleted rabbits by intraarticular injection of purified suspensions of neutrophils.

A requirement for complement was demonstrated in development of the lesion. Rabbits genetically deficient in C6 showed delay in vascular permeability, appearance of neutrophils, and histologic lesions. The delay was longer in normal rabbits depleted of $\mathrm{C} 3$. In C6-deficient rabbits depleted of $\mathrm{C} 3$, still further reduction in injury occurred.

Evidence was obtained as well for a chemotactic attraction of neutrophils in vivo. Antigen-antibody-complement complexes in the walls of blood vessels attracted neutrophils placed in the joint space of neutrophil-depleted rabbits. Omission of either antigen or antibody from this replacement reaction prevented the migration of neutrophils.

Dr. DeShazo is a fellow under the U. S. Public Health Service Graduate Training Grant in Surgery 5TO1 GM173346; his present address is the Department of Surgery, Southwestern Medical School, Dallas, Tex. 75235. Dr. Henson is the recipient of U. S. Public Health Service Career Development Award 5, kO4-GM-42567-02.

Received for publication 4 June 1971 and in revised form 12 August 1971.

\section{INTRODUCTION}

This study was undertaken to develop a model for examining the course of events, mediators, and products of acute immunologic injury in the whole animal. The knee joint was chosen as a natural, potential space into which injections might be made and from which fluid could be aspirated for study. The rabbit served as a convenient animal for evaluating immunologic reactions.

Previous reports on immunologic synovial injury have dealt with histologic changes in subacute or chronic phases. Such lesions were usually produced by intraarticular antigen given to immunized animals (1) or by repeated injections of performed complexes (2) or other phlogistic substances. Acute arthritis caused by monosodium urate crystals has been studied in the knee joints of dogs (3). Immunologic injury in vitro has shown that humoral products react with certain cells, especially neutrophils, to initiate release of injurious contents (4). Still other in vitro techniques employing the chemotaxis chamber (5) have demonstrated how inflammatory exudates can stimulate migration of neutrophils (6). At least three such factors are derived from complement: $\mathrm{C} 3 \mathrm{a}(7), \mathrm{C} 5 \mathrm{a}(8,9)$, and the $\overline{\mathrm{C567}}$ trimolecular complex (10). Their importance has become more evident with demonstration of decreased complement levels in human rheumatoid synovial fluids (11) and the finding of chemotactic factors in aspirate of inflamed joints (12).

We have limited our investigations to the hours immediately after initiating an Arthus type injury to study development of the early lesion. Multiple parameters were chosen to examine how vascular damage developed, what role neutrophils played, and how chemotactic factors might be involved. Uniform injury could be produced in this model, evaluated, abolished, then reconstituted, or selectively regulated. In the past it has not been possible to follow such acute inflammation in the experimental animal. Quantitation of injury should allow further study of mechanisms of cell release in vivo and evaluation of methods of altering the inflammatory response. 


\section{METHODS}

Experimental animals. Male $2.0 \mathrm{~kg}$ New Zealand rabbits were used in all experiments. Rabbits genetically deficient in C6 were derived from Mexican and English strains and bred locally.

Immunoreactants. Antibody to five times crystallized bovine serum albumin $(B S A)^{1}$ (Armour Pharmaceutical Co., Chicago, IIl.) was produced in rabbits using methods previously described (13). The antiserum was precipitated with ammonium sulfate at $50 \%$ saturation, and the resulting globulin fraction was passed over DEAE-cellulose at $\mathrm{pH}$ 8.0 in $0.02 \mathrm{M}$ phosphate buffer. The pooled effluent was sterilized by micropore filtration (Swinnex 25; Millipore Corp., Bedford, Mass.) and frozen in single use portions. Precipitin reaction was quantitated by the method of Heidelberger and Kendall as described by Kabat and Mayer (14). A noncomplement-fixing anti-BSA fractionated from serum of hyperimmune ducks (15) was used in other studies. Specific antigen (BSA) dissolved in pyrogen-free saline was sterilized and frozen in portions.

Production of a uniform synovial lesion. A reversed passive Arthus (RPA) injury was produced by injecting antibody into the knee, or stifle, joint of rabbits then giving specific antigen intravenously. Unanesthetized animals were held supine, and ethyl alcohol was sprayed over their knees. Anti-BSA, $300 \mu \mathrm{g}$ nitrogen in a $1 \mathrm{ml}$ volume was injected medial to the patella into the left knee joint cavity using a disposable tuberculin syringe and 27 gauge needle. A suitable control, usually pyrogen-free saline, was injected in the same manner into the right knee. Immediately thereafter $3 \mathrm{mg}$ BSA nitrogen was given into the lateral ear vein producing a circulating antigen level of $10-12 \mu \mathrm{g} / \mathrm{ml}$ of serum. The animals were then given $10 \mu \mathrm{Ci}$ of radiolabeled protein, usually $\mathrm{RSA}^{-125} \mathrm{I}$ (rabbit albumin) or TG${ }^{181}$ I (rabbit thyroglobulin), or both, i.v. After a selected time interval a blood sample was obtained for isotope counting. The animals were given $100 \mathrm{mg} / \mathrm{kg}$ carbon black (Pelikan, lot CII/1431A ; Günther-Wagner, Hanover, Germany) i.v. and sacrificed after $15 \mathrm{~min}$ with an overdose of sodium pentobarbitol. Each joint was immediately irrigated with 2.0 $\mathrm{ml}$ of saline containing $0.01 \mathrm{M}$ EDTA as anticoagulant. Irrigant was recovered by aspirating the joint with a 2.5 $\mathrm{ml}$ plastic syringe and 23 gauge needle introduced posterior to the medial condyle of the femur (to avoid blood vessels). The amount of fluid aspirated, usually $0.5-1.0 \mathrm{ml}$, was measured and put in a plastic test tube. Each joint was then bisected, and synovial tissue was removed both for formalin fixation and freezing for fluorescent antibody studies.

The assessment of injury was divided into three general categories. Leakage of circulating proteins from injured blood vessels into the joint space as part of the inflammatory exudate was one. Most of these proteins such as RSA and TG were passively involved, but rabbit fibrinogen was also used. Each marker was labeled by chloramine-T (16). After dialysis all were further purified by passage over Sephadex G-25 (Pharmacia Fine Chemicals, Inc., Piscataway, N. J.) or by animal passage to remove free ${ }^{225} \mathrm{I}$ or ${ }^{181}$ I remaining. Counts per minute in irrigant fluid and $1 \mathrm{ml}$ portions of serum from the same animal at the conclusion of the experiment were obtained using a well-type scintilla-

${ }^{1}$ Abbreviations used in this paper: BSA, bovine serum albumin; $\mathrm{CoF}$, anticomplementary factor of Naja naja cobra venom; RPA, reversed passive Arthus reaction; RSA, rabbit serum albumin; TG, rabbit thyroglobulin (kindly supplied by Doctors W. O. Weigle and Bruce Clinton). tion counter. Volume-adjusted activity in injured and control joints could then be compared. The amount of protein in the inflammatory exudate was determined by a micro$\mathrm{Kjeldahl}$ technique and expressed as micrograms of nitrogen/milliliter.

The second assessment of injury was the accumulation of leukocytes in the joint space at various times, measured by hemocytometer counts of white blood cells in joint irrigant. These cells proved to be $98 \%$ or greater polymorphonuclear neutrophils. Histologic indication of injury comprised the third category. Here evidence of carbon black deposition in and about vessels was sought, and edema, hemorrhage, and perivenular accumulation of neutrophils were graded.

Fluorescent studies. Synovial tissue was snap frozen, then kept at $-20^{\circ} \mathrm{C}$ until cut on a microtome in $7-\mu$ sections. Fluorescein isothiocyanate (Sigma Chemical Co., S. Louis, Mo.) was conjugated to rabbit anti-BSA or guinea pig antirabbit C3 antibody preparations by dialysis (17) and used for staining.

Neutrophil depletion. Nitrogen mustard in an i.v. dose of $1.75 \mathrm{mg} / \mathrm{kg}$ produced virtual agranulocytosis at $72 \mathrm{hr}$. Neutrophil counts of $150 / \mathrm{mm}^{3}$ or less were taken as evidence of satisfactory depletion. Platelet counts were reduced only $15-20 \%$ at this time. Depletion of neutrophils was also effected by sheep anti-rabbit neutrophil antibody (18). This antiserum was thoroughly absorbed with cells other than neutrophils and with plasma to ensure specificity.

Purification of polymorphonuclear leukocytes. Rabbit blood neutrophils for repletion studies in neutrophil-depleted animals were obtained by modification of a gelatin sedimentation technique previously described (19). Briefly, this method consisted of bleeding rabbits from an ear artery into acid citrate dextrose solution, centrifuging at $500 \mathrm{~g}$ for $20 \mathrm{~min}$, and aspirating the platelet-rich plasma and buffy coat (containing mononuclear cells). The neutrophil-red cell sediment was resuspended in $2.5 \%$ gelatin and allowed to settle by gravity at $37^{\circ} \mathrm{C}$ for $30 \mathrm{~min}$. The neutrophil-gelatin supernatant thus formed was aspirated, centrifuged at $225 \mathrm{~g}$ for $10 \mathrm{~min}$, and the cells washed with pyrogen-free saline. Such preparations were $85-95 \%$ neutrophils. The total yield was determined, and a final cell sediment was resuspended in saline to the desired concentration.

Studies with complement depletion. The anticomplementary properties of the venom of cobra Naja naja (Ross Allen's Reptile Institute, Inc., Silver Springs, Fla.) have recently been described in detail (20). In the present study cobra venom factor ( $\mathrm{CoF}$ ) was obtained by chromatography on DEAE Sephadex A-50 (Pharmacia Fine Chemicals, Inc.) It eluted in a fraction from a linear salt gradient at $0.22 \mathrm{M}$ ionic strength. Doses of $300 \mathrm{U} / \mathrm{kg}$ divided over 24 $\mathrm{hr}$ produced decomplementation evidenced by $85-90 \%$ depletion of activity in a hemolytic assay (21).

\section{RESULTS}

\section{Development of immunologic injury in the synovium}

Relationship of injury to dose of antibody. 24 rabbits were given varying doses of anti-BSA antibody intra-articularly, followed by a constant amount of BSA i.v. Control animals received antibody alone, and all animals were examined at $5 \mathrm{hr}$. The degree of injury (average points) was related to the dose of antibody as seen in Fig. 1 and was detectable with injec- 

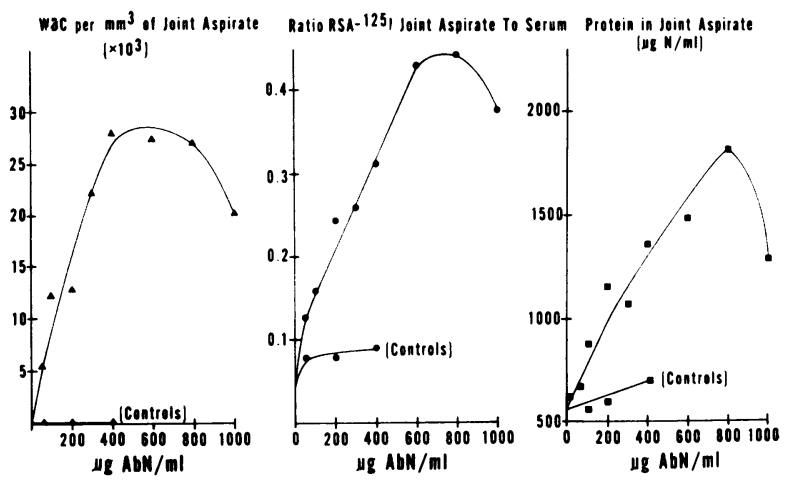

FIGURE 1 Response of RPA arthritis to increasing amounts of antibody. Anti-BSA was injected into the knee joints of 24 rabbits and antigen given i.v. Intra-articular antibody without i.v. antigen furnished controls. Parameters evaluated after $5 \mathrm{hr}$ (average points) included neutrophil count,

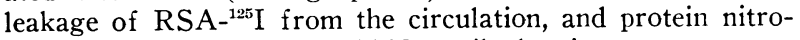
gen in the joint irrigant. $\mathrm{AbN}$, antibody nitrogen.

tions of as little as $50 \mu \mathrm{g}$. Injury was quantitated by the numbers of neutrophils, leakage of $\mathrm{RSA}{ }^{125} \mathrm{I}$ from the plasma, and increased quantities of protein in the joint irrigant. The degree of response to injections of antibody increased linearly to $600 \mu \mathrm{g}$, reached a plateau, then declined with $1000 \mu \mathrm{g}$. Control injections of antibody preparation without i.v. antigen evoked only minimal response. From these curves a dose of $300 \mu \mathrm{g}$ of antibody nitrogen was chosen for subsequent use in producing a unifom injury for comparison in other studies.

Synovial permeability. Initially a search was made for a marker suitable for measuring efflux from the joint into the plasma. Injections into the joint space of ${ }^{88} \mathrm{Rb}$, radioiodinated proteins including $\mathrm{RSA}$ and $\mathrm{TG}$ resulted in such rapid loss that good comparisons between developing lesions and controls could not be made. Only $5 \%$ of $\mathrm{RSA}^{-125} \mathrm{I}$ injected into the joint space was recovered after $60 \mathrm{~min}$. If a labeled marker was injected after inflammation had developed, however, its egress into the circulation was slightly more rapid than from controls when the plasma was examined at 5-min intervals. Aside from their rapid loss from the joint space, isotope preparations had some phlogistic properties which altered results. For these reasons isotope appearance in the serum was discarded in favor of its accumulation in the joint fluid from the circulation. Incorporation of this measure of synovial damage in the model is shown in Figs. 1 and 2.

Development of injury as a function of time. Fig. 2 shows the results of experiments in which a standard injury was produced and rabbits were evaluated serially. The increase in vascular permeability resulting from this Arthus type injury peaked at two times. Each of the radiolabeled proteins used showed a gradual in- crease in concentration in the joint irrigant of controls. In joints injected with antibody, however, a prompt exudation occurred becoming maximal at $2 \mathrm{hr}$. Over the next $4 \mathrm{hr}$ less radiolabeled and total protein was measured in the joint space. $7 \mathrm{hr}$ after injection a second increase in permeability began, reached its height at $8 \mathrm{hr}$, then also declined.

Histologic changes over the same time period were evaluated. As early as $30 \mathrm{~min}$ after joint injection, neutrophil margination and emigration from venules could be observed histologically, along with carbon deposition about the vessel walls. The number of neutrophils around venules in the superficial synovium continued to increase until the $5 \mathrm{th} \mathrm{hr}$, gradually obliterating the lumens of more vessels. The discrete lesions in the loose, reticular tissue of the synovium were striking (Fig. 3a). After this time the vascular lesions began to wane leaving hyalin deposits and nuclear debris. Animals examined up to $24 \mathrm{hr}$ showed gradual resolution of vascular lesions and reestablishment of patent lumens.

A few neutrophils were detectable in the joint irrigant as early as $2 \mathrm{hr}$ after injection. As seen in Fig. 2. their rapid rise did not occur until 5 and $6 \mathrm{hr}$ when the counts were consistently $10-11,000$ and $20,000 / \mathrm{mm}^{3}$, respectively. After the 7 th $\mathrm{hr}$ neutrophils became enmeshed in the inflammatory exudate, and counts became unreliable.

Labeled antigen in the synovium. The $\mathrm{BSA}{ }^{131} \mathrm{I}$ antigen was combined with the passively involved $\mathrm{RSA}^{-{ }^{125} \mathrm{I}}$ marker in paired label studies. Though the amount of labeled antigen in the circulation (BSA- ${ }^{131} \mathrm{I}$ counts per

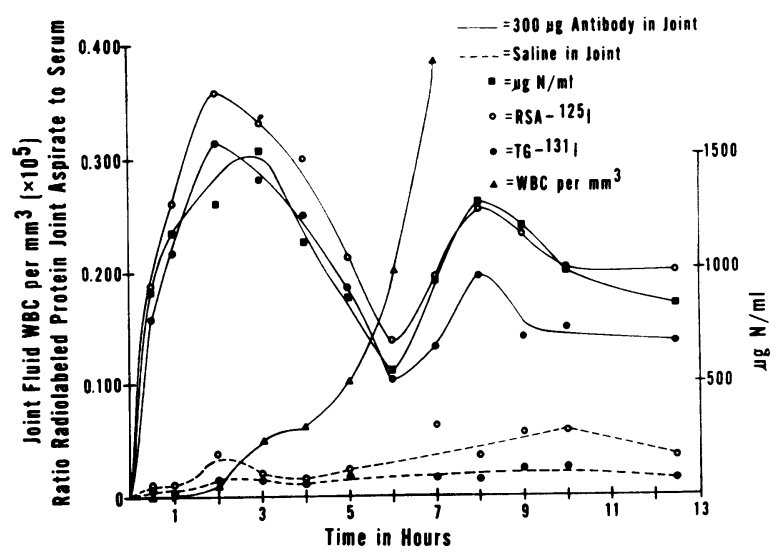

FIGURE 2 Immunologic arthritis developing with time. Rabbits were injected with anti-BSA in one knee and saline in the contralateral joint. They were then given $3000 \mu \mathrm{g}$ antigen i.v. and examined at intervals. Appearance of $\mathrm{RSA}^{-125} \mathrm{I}$ $(\mathrm{mol} \mathrm{wt}=69,000)$ and $\mathrm{TG}^{-131} \mathrm{I}\left(\mathrm{mol} \mathrm{wt}^{-1}=690,000\right)$ given i.v. was measured in the joint irrigant as an indication of increased vascular permeability. The amount of protein $(\mu \mathrm{g} / \mathrm{ml})$ and number of neutrophils (per $\mathrm{mm}^{3}$ ) were also determined at each time. Each point represents the mean of at least two joints. 

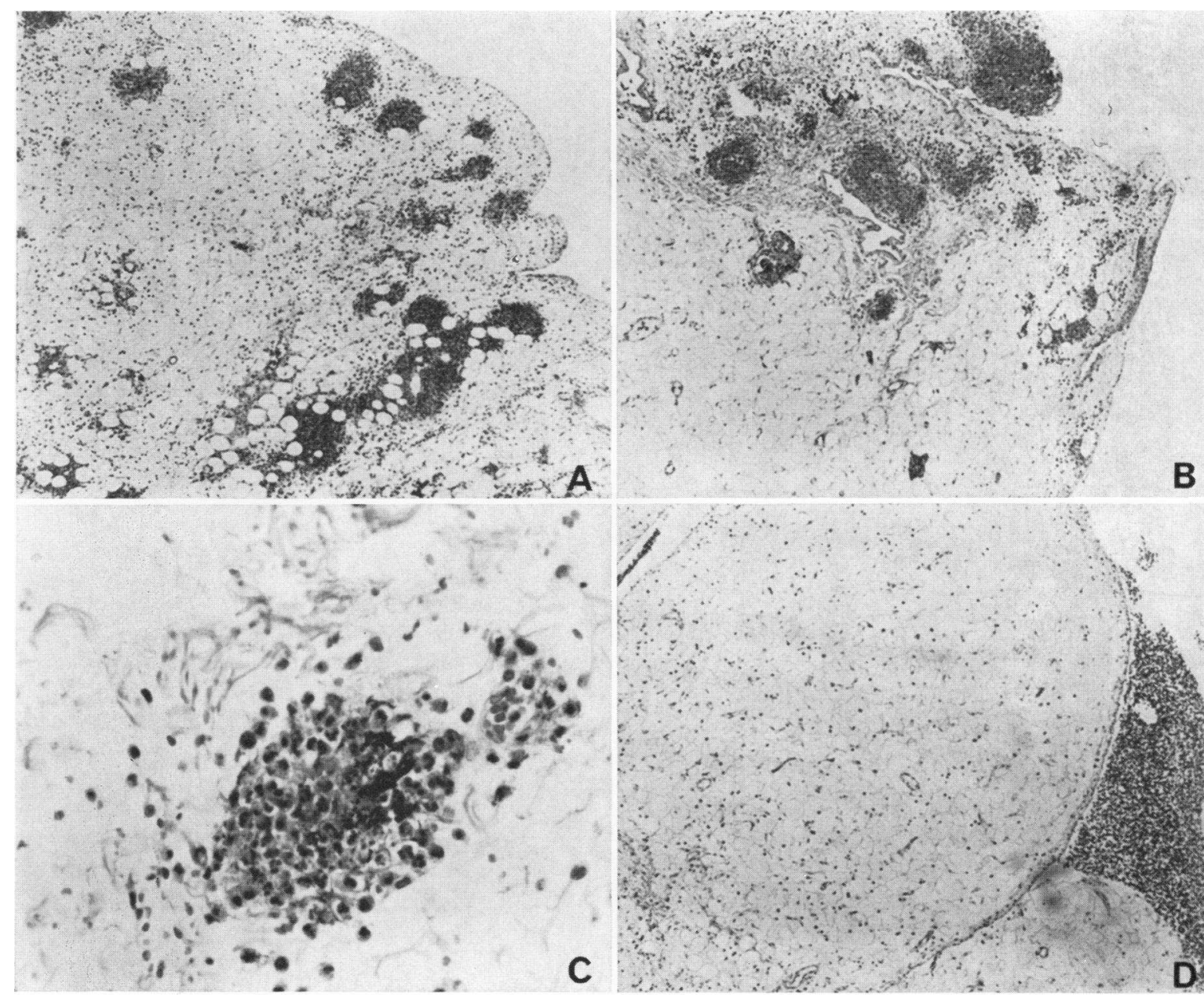

$B$

FIGURE 3 Photomicrographs of rabbit synovium showing replacement of RPA lesions with neutrophils. (A) RPA lesions in normal rabbit joints at $5 \mathrm{hr}$. Neutrophils are concentrated around venules and obliterating their lumens. $\times 62$. (B) RPA reestablished in a neutrophildepleted rabbit by $1 \times 10^{8}$ neutrophils given into the joint along with $300 \mu \mathrm{g}$ antibody, then i.v. antigen. $\times 62$. (C) Replacement lesions as in $3 \mathrm{~B}$ at $5 \mathrm{hr}$ showing carbon deposition and a histologically typical Arthus lesion. $\times 400$. (D) Control for $3 \mathrm{~B}$ : another neutrophil-depleted rabbit given $1 \times 10^{8}$ neutrophils from the same suspension and antibody into joint without i.v. antigen. No vascular lesions developed. $\times 62$.

minute) was usually 5 times greater than the rabbit albumin marker, less of it appeared in joint irrigant at $2 \mathrm{hr}$ than the $\mathrm{RSA}-{ }^{125} \mathrm{I}$. Determination of each isotope in counts per gram of synovial tissue at $2 \mathrm{hr}$ showed a preferential binding of antigen in injured joints, which was 10 times the level of that in contralateral control synovium. Precipitation of joint fluid with ammonium sulfate ( $50 \%$ of saturation) was performed to determine the amount of $\mathrm{BSA}-{ }^{131} \mathrm{I}$ bound to globulin at 2 and $6 \mathrm{hr}$ after injection of the antigen. The levels of nonprecipitable and precipitable $\mathrm{BSA}_{-}{ }^{125} \mathrm{I}$ antigen present early in lesser amounts, however, rose sharply by $6 \mathrm{hr}$. The amount of precipitable antigen, presumably complexed to residual antibody in the joint, was 15 -fold higher at the later time. Antigen was also present at $6 \mathrm{hr}$ in washed joint fluid neutrophils.

\section{Role of neutrophils in synovial injury}

Effect of neutrophil depletion. Normal animals given an RPA stimulus developed Arthus lesions around venules, and neutrophils appeared in the joint irrigant as just described. Depletion of peripheral neutrophils in rabbits by nitrogen mustard prevented development of vascular permeability and histologic evidence of injury. Measurements of permeability made at 15 and 30 min after injection, as well as at the times isotope loss was maximal in normal animals ( 2 and $8 \mathrm{hr}$ ), were the same for animals depleted of neutrophils as the normal 


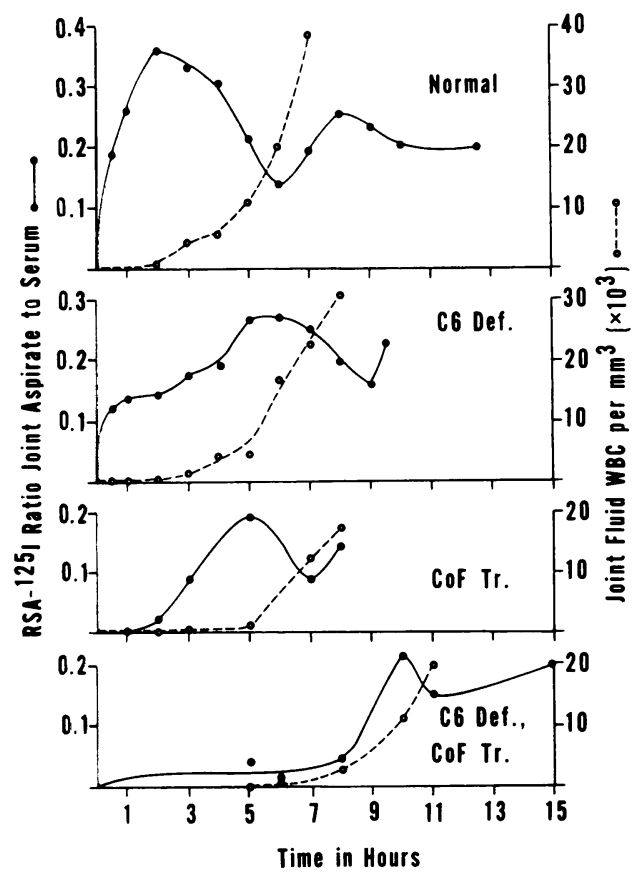

FigUre 4 Alterations in RPA joint injury caused by complement depletion. Rabbits genetically deficient in C6 (C6 Def.), depleted of $\mathrm{C} 3$ by cobra venom factor ( $\mathrm{CoF} \mathrm{Tr}$.), or both (C6 Def., CoF Tr.) were compared with normals in development of vascular permeability and neutrophil accumulation. An additive effect is seen.

animal controls shown in Fig. 2. In confirmatory studies depletion of neutrophils with sheep anti-rabbit neutrophil antibody also prevented development of any detectable increase in permeability.

Restoration of RPA injury by replacement of neutrophils. Reconstitution of RPA arthritis was achieved in neutrophil-depleted animals by replacing these cells. Animals depleted of neutrophils with nitrogen mustard were given rabbit blood neutrophils and antibody into the joint space, then antigen i.v. A perivascular lesion histologically indistinguishable from that in normal animals (compare Fig. $3 a$ with $3 b$ and $3 c$ ) could be produced by injecting $1 \times 10^{8}$ neutrophils into the joint space. The increased permeability measured at $5 \mathrm{hr}$ in this reconstituted lesion was 3-5 times that in joints receiving cells and antibody but without i.v. antigen to complete the reaction. Neutrophils infused without both antibody and antigen showed no histological evidence of directional movement, and few entered the synovium (Fig. 3d). For control studies rabbit blood was separated into erythrocyte, mononuclear cell, neutrophil, and platelet fractions (the latter in a concentration 25 times that contaminating the usual neutrophil preparation). Portions of each component were introduced into different joints, but only the neutrophils produced injury. As few as $2.5 \times 10^{7}$ neutrophils could reconstitute a detectable injury, and although larger numbers augmented it somewhat, a graded injury to increasing numbers of cells was difficult to establish. Joints in animals with neutrophil replacement were examined for as long as $36 \mathrm{hr}$. Neutrophils around venules diminished over this time, while mononuclear cells were still seen in areas of injury at $36 \mathrm{hr}$.

\section{Participation of complement in neutrophil migration}

C6-deficient rabbits. After determining that neutrophils placed in the joint space accumulated around synovial vessels in the replacement studies, experiments were designed to determine a cause. C6-deficient rabbits were compared with normal rabbits hour by hour, and permeability, measured by leakage of circulating isotope, was delayed (Fig. 4). Leakage of $\mathrm{RSA}^{-125} \mathrm{I}$ began promptly, though it was one-third less than the normal levels at $30 \mathrm{~min}$. At $2 \mathrm{hr}$ when permeability in normal rabbits had become maximal, permeability in C6-deficient animals had not progressed. It was not until 6 hr after injection that the rate of leakage in these C6deficient rabbits reached that in normal ones. Changes in protein nitrogen levels in the exudate (not shown) paralleled closely those of the isotope as it had in other studies.

Vascular lesions observed histologically in synovium of C6-deficient rabbits were also delayed. A few neutrophils accumulated around venules at $30 \mathrm{~min}$, but the appearance of the lesions did not progress appreciably for another $3 \mathrm{hr}$. By $5 \mathrm{hr}$ these lesions appeared the same as those in normal animals. As can be seen from Fig. 4, the appearance of neutrophils in the joint space was also somewhat retarded. These variations from normal applied only to homozygous C6-deficient rabbits for their heterozygotes developed lesions just like the New Zealand strain. C6-deficient rabbits were treated with nitrogen mustard and used in replacement experiments. Neutrophils from New Zealand rabbits were infused into joints of such rabbits in the manner described above. The neutrophil accumulation around venules was significantly less intense than that in neutrophil-depleted New Zealand rabbits receiving injections to serve as positive controls for the cell suspensions.

C3-depleted rabbits. The level of hemolytic complement in New Zealand rabbits was decreased to $7-15 \%$ of normal by repeated injections of $\mathrm{CoF}$. In these $\mathrm{C} 3$ depleted animals the appearance of vascular permeability with the usual RPA injury was markedly delayed. Fig. 4 shows that the highest rate of permeability increase attained in these animals was only half that of normal ones. At $2 \mathrm{hr}$, the time of maximal permeability of normal rabbits, $\mathrm{CoF}$-treated animals with antibody in 
TABLE I

Reversed Passive Arthus Arthritis, Comparison with Effect of Duck* to Rabbit $\ddagger$ Antibody

\begin{tabular}{|c|c|c|c|c|}
\hline & $\begin{array}{c}\text { Permeability } \\
\text { ratio RSA-12sI } \\
\text { counts } \\
\text { joint/serum }\end{array}$ & $\begin{array}{c}\text { Neutrophil } \\
\text { count } \\
\text { per } \mathrm{mm}^{\mathrm{s}}\end{array}$ & $\begin{array}{l}\text { Protein } \\
\text { in joint } \\
\text { aspirate }\end{array}$ & $\begin{array}{c}\text { Histologic } \\
\text { vessel } \\
\text { lesions }\end{array}$ \\
\hline & & & $\mu g \mathrm{~N} / \mathrm{ml}$ & \\
\hline $\begin{array}{l}\text { Duck anti-BSA control } \\
\text { (antibody in joint }\end{array}$ & 0.070 & 1,200 & 735 & None \\
\hline \multicolumn{5}{|l|}{ Duck anti-BSA injury } \\
\hline $\begin{array}{l}200 \mu g \text { nitrogen } \\
\text { Rabbit anti-BSA control } \\
\text { (antibody in joint }\end{array}$ & 0.111 & 3,600 & 660 & None \\
\hline without i.v. antigen) & 0.068 & 200 & 650 & None \\
\hline Rabbit anti-BSA injury & & & & Neutrophils \\
\hline $200 \mu \mathrm{g}$ nitrogen & 0.287 & 14,100 & 1070 & $\begin{array}{l}\text { and carbon } \\
\text { deposition }\end{array}$ \\
\hline
\end{tabular}

* Duck anti-BSA demonstrated to be noncomplement-fixing in assay measuring complement consumption from rabbit serum.

$\ddagger$ Rabbit anti-BSA preparation used in other studies, compared directly with duck preparation in contralateral joint.

the joints showed no more permeability than saline controls. Maximum permeability in C3-depleted rabbits was reached at $5 \mathrm{hr}$ but was little more than half the level achieved in normal rabbits.

Histological lesions in rabbits treated with $\mathrm{CoF}$ did not develop in the early hours. Appearance of neutrophils in the joint space was also retarded. In normal rabbits the counts at 3 and $7 \mathrm{hr}$ were $10-11,000$ and $38,000 / \mathrm{mm}^{3}$, respectively, while in $\mathrm{CoF}$-treated animals values of 1400 and 12,500 were observed at these times. Neutrophil replacement lesions in neutrophil depleted, C3-depleted rabbits showed less vascular permeability and fewer neutrophils at sites of antigen-antibody reaction in vessel walls at $5 \mathrm{hr}$.

C6-deficient rabbits treated with CoF. Experiments were performed to determine whether the effects of C6 deficiency together with C3 depletion would further reduce the accumulation of neutrophils and injury of RPA arthritis. When C6-deficient rabbits were treated with $\mathrm{CoF}$, significant permeability did not occur until the 10th $\mathrm{hr}$ and was never as pronounced as in normal animals (Fig. 4).

The histologic picture in the late developing lesions here was mixed. Generally minimal vascular injury occurred, but a few actively developing lesions mixed with regressing lesions were seen. Migration of neutrophils into the joint space was also delayed until about $10 \mathrm{hr}$ after the reaction had begun.

Noncomplement-fixing antibody. Preparations of duck anti-BSA antiserum were fractionated to obtain an antibody that did not utilize complement. This antibody was compared with the complement-fixing rabbit antibody used above. Equal amounts of antibody nitrogen of each preparation were injected into opposite knee joints of the same rabbit and antigen given i.v. RPA injury developed undiminished in joints receiving rabbit antibody, but the duck antibody did not cause vascular lesions. The results are give in Table I. Controls for the duck antibody (antibody with no i.v. antigen) showed the preparations had inherent inflammatory effects that have been previously recognized. Thus duck antibody evoked some increase in permeability and neutrophil accumulation in the joint space, but the injury with rabbit antibody was always several times greater. The clearest difference between the two was the histologic absence of RPA vascular lesions with duck antibody.

Fluorescent antibody studies. Sections of synovial tissue were stained with fluorescein-conjugated antibody. In this way it was possible to confirm the deposition of immune complexes and $\mathrm{C} 3$ in the venules of injured joints. They were present in synovium of normal New Zealand animals 30 and $60 \mathrm{~min}$ after injection. After $2 \mathrm{hr}$ complexes could not be found in normal rabbits. For comparison, RPA was produced simultaneously in C6-deficient animals where vascular permeability and neutrophil accumulation was delayed. Here complexes were not rapidly degraded and were still clearly evident at $2 \mathrm{hr}$. Similar deposits were found at these times when staining was done with the conjugated anti-C3 antibody. 


\section{DISCUSSION}

These results indicate that it is possible to quantitate certain aspects of acute immunologic injury in vivo and to correlate functional events with histologic observations. The essential role of neutrophils in this Arthus type lesion was shown not only by depletion studies, but also by direct intraarticular replacement of these cells. In the presence of antibody in the joint and circulating antigen, neutrophils in such replacement experiments migrated from the joint space to venules in the synovium. Neutrophils in these reconstituted lesions decreased in number leaving a phase of mononuclear predominance. Replacement experiments such as these should make it possible to alter specific neutrophil functions in vitro and to return the cells to homologous animals to study their function in vivo. Another feature of this model is that it allows recovery of components of the inflammatory process at various times during the development of injury.

The development of these reversed Arthus lesions can be explained by the fact that when a solution is injected into the joint space it enters the circulation through venules in the synovium (22). When antibody diffusing from the joint space meets circulating antigen, precipitation of immune complexes in the vessel wall ensues. Sparse intercellular bridges and lack of basement membrane in the synovial lining $(23,24)$ allow free diffusion in and out of the joint space. The similar permeability results we obtained with molecules varying greatly in size (albumin and thyroglobulin) agree with the findings of Sliwinski and Zvaifler (25). Their studies showed a similar rate of loss of albumin and IgG from the knee joint.

The fact that our results showed a much faster loss of substances from the joint than those of Rodnan and MacLachlan (our $5 \%$ recovery at $1 \mathrm{hr}$ vs. their $25 \%$ remaining after $24 \mathrm{hr}$ ) was probably because we calculated percentage of injected dose actually recovered from the joint. Their results were made by collimated external counting over the whole joint (26). These observations meant that, for this model, static measurements made on arthritic exudate could best be used for comparison with results from other joints rather than as some indicator of total injury produced. Even so, the parameters employed reflected events of the ongoing, dynamic process reliably and with sensitivity.

The studies of complement depletion indicated how chemotactic factors might function in the development of this lesion in vivo. The slower rate of injury developing in C6-deficient rabbits suggested interference with formation of the $\mathrm{C} \overline{567}$ trimolecular complex and offered evidence that this factor participates in chemotaxis in vivo. Alternatively, in the absence of $\mathrm{C} 6$, the rate of $\mathrm{C} 5$ interaction and formation of $\mathrm{C} 5 \mathrm{a}$ might be diminished (27). Our demonstration of $\mathrm{C} 3$ in these immune precipitates by fluorescent antibodies meant that this molecule was available to form the chemotactically active $\mathrm{C} 3 \mathrm{a}$ fragment and to cause the lesion to progress.

When the level of $\mathrm{C} 3$ had been reduced by $\mathrm{CoF}$, development of early histologic lesions and permeability were diminished or abolished. Some C3 was always available and depletion never complete. Presumably, with time, remaining $\mathrm{C} 3$ could generate some active fragment. Once the reaction began, chemotactic factors C5a and $\mathrm{C} \overline{567}$ generated later in the sequence would appear. Important to this interpretation were the observations that neutrophils from C6-deficient and $\mathrm{CoF}$ treated rabbits released enzymes normally during phagocytosis (19) and exhibited normal chemotaxis and immune adherence in vitro (20).

Neutrophil replacement studies in rabbits lacking complement components showed diminished neutrophil accumulation and less vascular permeability as well. Thus it has been possible to show that replacement of neutrophils alone will restore the Arthus lesion and that complement depletion will alter their movement to immune complexes in vessel walls. This method avoids the perennial criticisms both of possible side effects from producing agranulocytosis with nitrogen mustard and of having to use whole blood to reconstitute the lesion. Failure of noncomplement-fixing antibody (avian) to produce an RPA lesion gave still more substance to our contention that complement-derived chemotactic factors play an important role in the development of this experimental immunologic lesion.

The diaphanous appearance of synovial tissue in histologic sections made it an excellent site for following histologic development of Arthus lesions (Fig. 3). In injured joints of normal animals neutrophils accumulated rapidly around venules. Fluorescent antibody was used to demonstrate the presence, then degradation of immune complexes around venules. Lumens became obliterated by neutrophil plugs, and new vessels became patent. After $5 \mathrm{hr}$ the number of neutrophils decreased and lesions began to resolve. leaving eosinophilic deposits and nuclear debris. At later hours neutrophils accumulated under the synovial lining as more of them entered the joint space and became enmeshed in the inflammatory exudate.

The finding of two peaks of activity in vascular permeability suggested that more than simple venular injury due to Arthus lesions was taking place. Leakage of circulating radiolabeled proteins began almost immediately after injection into injured joints. It achieved a maximal rate at $2 \mathrm{hr}$ when migration of neutrophils across vessel walls was most intense. The molecular size of isotope markers (i.e., rabbit albumin and thyroglobulin) did not alter the time at which they entered 
the joint (Fig. 2). This indicated that despite the size difference between the radiolabeled proteins, damage to vessel wall integrity by neutrophils was too great to impede their passage.

The rise in permeability at $8 \mathrm{hr}$ took place as vascular lesions were decreasing and the inflammation within the joint space itself grew more intense. This secondary peak in permeability probably has more than one cause. It was difficult to study because it could not be separated from the initial period of vascular damage. The finding of increasing numbers of neutrophils in the joint space at this time may explain part of the permeability. Labeling of the antigen in some experiments allowed demonstration of immune complexes in the joint space at later hours. As complexes formed and were phagocytosed, anaphylotoxins derived from complement components and soluble products from neutrophils might diffuse back into the synovium to initiate a secondary injury.

\section{ACKNOWLEDGMENTS}

Miss Maureen T. McGrade made valuable contributions to all phases of this study.

This work was supported in part by U. S. Public Health Service Grant AI-07007.

\section{REFERENCES}

1. Loewi, G. 1969. Experimental immune inflammation in the synovial membrane. II. The origin and local activity of inflammatory cells. Immunology. 17: 489.

2. Rawson, A. J., and T. P. Torralba. 1967. Induction of proliferative synovitis in rabbits by intra-articular injection of immune complexes. Arthritis Rheum. 10: 44.

3. McCarty, D. J., P. Phelps, and J. Pyenson. 1966. Crystal-induced inflammation in canine joints. I. An experimental model with quantification of the host response. J. Exp. Med. 124: 99.

4. Cochrane, C. G. 1968. Immunologic tissue injury mediated by neutrophilic leukocytes. Advan. Immunol. 9: 97.

5. Boyden, S. 1962. The chemotactic effect of mixtures of antibody and antigen on polymorphonuclear leucocytes. J. Exp. Med. 115: 453.

6. Ward, P. A. 1970. Neutrophil chemotactic factors and related clinical disorders. Arthritis Rheum. 13: 181.

7. Ward, P. A. 1967. A plasmin-split fragment of $C^{\prime} 3$ as a new chemotactic factor. J. Exp. Med. 126: 189.

8. Ward, P. A., and L. J. Newman. 1969. A neutrophil chemotactic factor from human $C^{\prime} 5$. J. Immunol. 102: 93.

9. Shin, H. S., R. J. Pickering, M. M. Mayer, and C. T. Cook. 1968. Guinea pig C'5. J. Immunol. 101: 813.

10. Ward, P. A., C. G. Cochrane, and H. J. Müller-Eberhard. 1965. The role of complement in chemotaxis of leukocytes in vitro. J. Exp. Med. 122: 327.
11. Ruddy, S., and K. F. Austin. 1970. The complement system in rheumatoid synovitis. I. An analysis of complement component activities in rheumatoid synovial fluids. Arthritis Rheum. 13: 713.

12. Ward, P. A., and N. J. Zvaifler. 1971. Complementderived leukotactic factors in inflammatory synovial fluids of humans. J. Clin. Invest. 50: 606.

13. Johnson, A. G., S. Gaines, and M. Landy. 1956. Studies on the $\mathrm{O}$ antigen of Salmonella typhosa. V. Enhancement of antibody response to protein antigens by the purified lipopolysaccharide. J. Exp. Med. 103: 225.

14. Kabat, E. A., and M. M. Mayer. 1961. Experimental Immunochemistry. Charles C. Thomas, Publisher, Springfield, I11. 2nd Edition. 72.

15. Grey, H. M. 1967. Duck immunoglobulins. I. Structural studies on a $5.7 \mathrm{~S}$ and $7.8 \mathrm{~S} \gamma$-globulin. J. Immunol. 98: 811 .

16. McConahey, P. J., and F. J. Dixon. 1966. A method of trace iodination of proteins for immunologic studies. Int. Arch. Allergy Appl. Immunol. 29: 185.

17. Clark, H. F., and C. C. Shepard. 1963. A dialysis technique for preparing fluorescent antibody. Virology. 20: 642.

18. Kniker, W. T., and C. G. Cochrane. 1965. Pathogenic factors in vascular lesions of experimental serum sickness. J. Exp. Med. 122 : 83.

19. Henson, P. M. 1971. The immunologic release of constituents from neutrophil leukocytes. I. The role of antibody and complement on nonphagocytosable surfaces or phagocytosable particles. J. Immunol. 107. In press.

20. Cochrane, C. G., H. J. Müller-Eberhard, and B. S. Aikin. 1970. Depletion of plasma complement in vivo by a protein of cobra venom: its effect on various immunologic reactions. J. Immunol. 105: 55.

21. Osler, A. G., J. H. Strauss, and M. M. Mayer. 1952. Diagnostic complement fixation. I. A method. Amer. J. Syph. Gonor. Vener. Dis. 36: 140.

22. Adkins, E. W. O., and D. V. Davies. 1940. Absorption from the joint cavity. Quart. J. Exp. Physiol. Cog. Med. Sci. 30: 147 .

23. Barland. P., A. B. Novikoff, and D. Hamerman. 1962. Electron microscopy of the human synovial membrane. J. Cell Biol. 14: 207.

24. Norton, W. L., and M. Ziff. 1966. Electron microscopic observations on the rheumatoid synovial membrane. Arthritis Rheum. 9: 589.

25. Sliwinski, A. J., and N. J. Zvaifler. 1969. The removal of aggregated and nonaggregated autologous gamma globulin from rheumatoid joints. Arthritis Rheum. 12: 504.

26. Rodnan, G. P., and M. J. MacLachlan. 1960. The absorption of serum albumin and gamma globulin from the knee joint of man and rabbit. Arthritis Rheum. 3: 152.

27. Nilsson, U. R., and H. J. Müller-Eberhard. 1967. Studies on the mode of action of the fifth, sixth, and seventh component of human complement in immune haemolysis. Immunology. 13: 101. 